\title{
The Italian NHS at regional level: same in theory, different in practice
}

\author{
Livio Garattini ${ }^{1} \cdot$ Marco Badinella Martini $^{1} \cdot$ Michele Zanetti $^{1}$
}

Accepted: 6 May 2021 / Published online: 19 May 2021

(c) The Author(s), under exclusive licence to Springer-Verlag GmbH Germany, part of Springer Nature 2021

\begin{tabular}{|c|c|}
\hline \multicolumn{2}{|c|}{ Abbreviations } \\
\hline \multicolumn{2}{|c|}{ Legend of Italian acronyms } \\
\hline AGENAS & $\begin{array}{l}\text { AGEnzia NAzionale per i Servizi sanitari } \\
\text { regionali }\end{array}$ \\
\hline L.R. & Legge Regionale \\
\hline \multicolumn{2}{|l|}{ Veneto } \\
\hline $\mathrm{AO}$ & Azienda Ospedaliera \\
\hline AULSS & Azienda Unità Locale Socio-Sanitaria \\
\hline $\mathrm{AZ}$ & Azienda Zero \\
\hline \multicolumn{2}{|l|}{ Lombardy } \\
\hline ACSS & $\begin{array}{l}\text { Agenzia di Controllo del Sistema } \\
\text { Socio-sanitario }\end{array}$ \\
\hline AREU & Agenzia Regionale Emergenza Urgenza \\
\hline ARIA & $\begin{array}{l}\text { Azienda Regionale per Innovazione e } \\
\text { Acquisti }\end{array}$ \\
\hline ASST & Azienda Socio-Sanitaria Territoriale \\
\hline ATS & Agenzia Tutela Salute \\
\hline
\end{tabular}

\section{Introduction}

Italy is a large European continental country of around 60 million inhabitants. The Italian territory is divided into 20 regions, all governed by elected politicians, which vary a lot in terms of both size and population [1].

To govern health care, since 1976 Italy has adopted a National Health Service (NHS), which provides universal coverage mostly funded by general taxation and services largely free of charge at the point of delivery [2]. Starting from 1992, the Italian NHS has been increasingly decentralized, with many powers devolved to regions. Thanks to local autonomy, regions are allowed to develop substantially different health strategies, without necessarily national endorsement [3]. Health is by far the most important item

Livio Garattini

livio.garattini@marionegri.it

1 Institute for Pharmacological Research Mario Negri IRCCS, Milan, Italy of all regional budgets, thus a major political topic for local elections. This has gradually transformed the Italian NHS into several uneven regional health services (RHSs) within the same country [1].

Italy was the first European country dramatically hit by the COVID-19 pandemic in early 2020, especially in the North, the wealthiest and most productive area of the country. In particular, the number of victims was dramatically high in Lombardy (capital Milan), whilst much lower in Veneto (capital Venice), the two neighboring regions (with similar socioeconomic features) first hit by the pandemic [4]. In general, this striking contrast has been traced back to a traditionally more integrated care between community and hospital services in Veneto, ultimately boosting more effective clinical measures in terms of public health [5]. Conversely, a hospital-centered care might have substantially penalized Lombardy, where accident and emergency services (AEs) were the sites of the first COVID-19 outbreaks.

Here, we first summarize and compare the main characteristics of the two RHS frameworks, with a specific focus on acute hospitals, the most important hospital category. Then, we try to generalize some policy implications drawn from this comparison, and finally put forward some proposals to redesign health policy in the NHS.

\section{Veneto}

Veneto is a large region $\left(18,345 \mathrm{~km}^{2}\right)$ of around 5 million inhabitants located in the North-East of Italy. It has been always governed in the last decades by centre-right political coalitions, with the regionalist Northern League party recently dominant in all its counties.

A regional law issued in 2016 (L.R. 19/2016) has enacted the most recent and relevant health reforms. The RHS is now divided into nine local health authorities (LHA, AULSS), headed by general managers appointed at the regional level. LHAs manage all the healthcare services delivered within their territory. The only exceptions are three autonomous hospital trusts $(A O)$, of which two include the biggest hospitals in the region (Padua and Verona) and the third one is 
fully specialized in oncology. The territory of each LHA is subdivided in districts, operational units that should organize (in coordination with local hospitals) the existing primary care services delivered in the community through public or private accredited facilities [6]. Overall, there are now 26 districts, which basically reflect the territories of the former LHAs before their drastic reduction by the last reform.

Since 2016 the vast majority of central bodies have been merged in a single agency $(A Z)$, which is responsible for LHAs' funding, planning, accounting, auditing and job posting. Furthermore, this agency is in charge of regional tenders and health technology assessments, and is allowed to conduct data analyses to support all its activities.

Starting from 2016 acute hospital facilities are systematically classified into a 'hub and spoke' conceptual network [7]. This has been the last step of a long (still ongoing) process aimed at resetting the number of smaller acute hospitals that do not adequately meet safety and quality standards [8]. At present, there are (i) 8 hubs at the top for completeness of clinical departments (the 3 hospital trusts included, defined hubs of excellence), (ii) 20 spokes (of which 2 private accredited hospitals) including medium- and basic-level departments to fulfill local catchment areas, and (iii) 8 nodes (of which 1 private accredited hospital) with basic departments placed in remote areas. All these hospitals have an AEs.

\section{Lombardy}

Lombardy $\left(23,863 \mathrm{~km}^{2}\right)$ lies in the centre of Northern Italy and is the most populated region of the country, with around 10 million inhabitants ( 3.5 million of them resident in the metropolitan area of Milan). Although traditionally characterized by a quite uneven political situation at the county level (especially different in Milan and suburbs), Lombardy has been mainly governed by centre-right political coalitions in the last decades.

Historically, Lombardy is the Italian region that has trusted most in a complete purchaser-provider split to foster market competition among the latter in its RHS [2], especially between public and private hospitals. A regional law issued in 2015 (L.R. 23/2015) has drastically reformed the RHS local tier by separating the health services' planning, purchasing and control from their provision on the regional territory. Accordingly, the first tasks have been devolved to 8 health protection agencies (HPA, ATS), while public healthcare provision to 27 health territorial authorities (HTA, $A S S T)$. In particular, HPAs manage all contracts, accredit private health providers (e.g., hospitals and all general practices), and allocate the regional funds to them and HTAs. In turn, HTAs organize the supply of all public healthcare services delivered on their territory by dividing them in two poles: community (general practices excluded) and hospital services. HPAs and HTAs are all headed by general managers appointed at the regional level. The number of HTAs supervised by each HPA varies from one to nine (in the metropolitan HPA of Milan). The territories of districts coincide with those of the 27 HTAs, but HPAs can decide to subdivide them into district areas (currently 92 in total). Although districts are operational units aimed at delivering community services, their planning depends on HPAs.

To complete the picture, there are many central agencies, of which are worth quoting for the relevance of their manpower the three for auditing (ACSS), tendering (ARIA) and emergency (AREU).

The number of acute hospitals working on behalf of the RHS is very high and, lacking a formal classification of single facilities, it proves hard to accurately quantify them. By adopting the presence of an AEs as a pre-requisite for selection, we found 68 public hospitals managed by the HTAs and 29 private hospitals accredited by the HPAs, overall 97 acute hospitals (of which 16 located in Milan municipality).

Finally, it is worthwhile remarking that the National Agency for RHSs (AGENAS) has recently issued a critical report on the last Lombardy reform [9], arguing that the new framework fragmented the RHS in too many agencies despite its positive aim to integrate community and hospital services. To recoup the RHS governance, the national agency has warmly recommended to (i) merge the eight local HPAs in one central agency, (ii) carefully reconsider the sizes of HTAs, and (iii) assign the management of districts entirely to HTAs.

\section{Comparative analysis}

Lombardy and Veneto are two wealthy neighboring regions, not so different from a physical geography perspective too. Although the territory of Lombardy is about 1/4 larger, the proportions between low-lying and mountain areas are rather similar. Moreover, although the population is approximately $1 / 2$ lower in Veneto, this difference is mainly due to the metropolitan area of Milan, by far the major catchment of Lombardy population. Last but not least for the scope of our comparison, even the political contexts of these two regions have become quite similar in the last decades.

Despite all these similarities, the organizational frameworks of the two RHSs have become increasingly different, with scant justification related to the peculiarity of the Milan area. Nowadays there are 13 important authorities and agencies in Veneto region, whereas at least 38 are in Lombardy altogether, many of them somehow intertwined and overlapping. This roughly three times higher number of bodies inevitably makes much more complex the clinical governance of the RHS in Lombardy [3]. 
The density of acute hospitals in Veneto is almost $1 / 3$ less by population and half less by surface compared to Lombardy, with very unevenly scattered facilities on the two territories after taking account of Milan metropolis too (Fig. 1). In addition to the traditionally much higher number of private hospitals, even that of small-sized acute hospitals is now disproportionately higher in Lombardy (Fig. 2), and the gap between the distributions of the two hospital networks is likely to have increased during the last decades. While the strategy planned in Veneto to increase efficiency within the acute hospital network has constrained small facilities in the long run, the 'quasi market' strategy aimed at thrusting competition between hospitals has not achieved similar results in Lombardy.

\section{Policy implications}

The very heterogeneous frameworks of the two RHSs analyzed confirm that the organization and management of healthcare services delivered within the universal tax-funded Italian NHS have been shaped in very different ways [2], even in geographically, economically and politically similar regions. In particular, the organizational consistency of the three-tiered (central, regional, local) Italian NHS is undermined by regional autonomy, which makes it very prone to influence from local policies and economies [1]. Although with much less realities at the intermediate tier, something similar has happened in the British NHS, with nations instead of regions. For instance, the English NHS has been

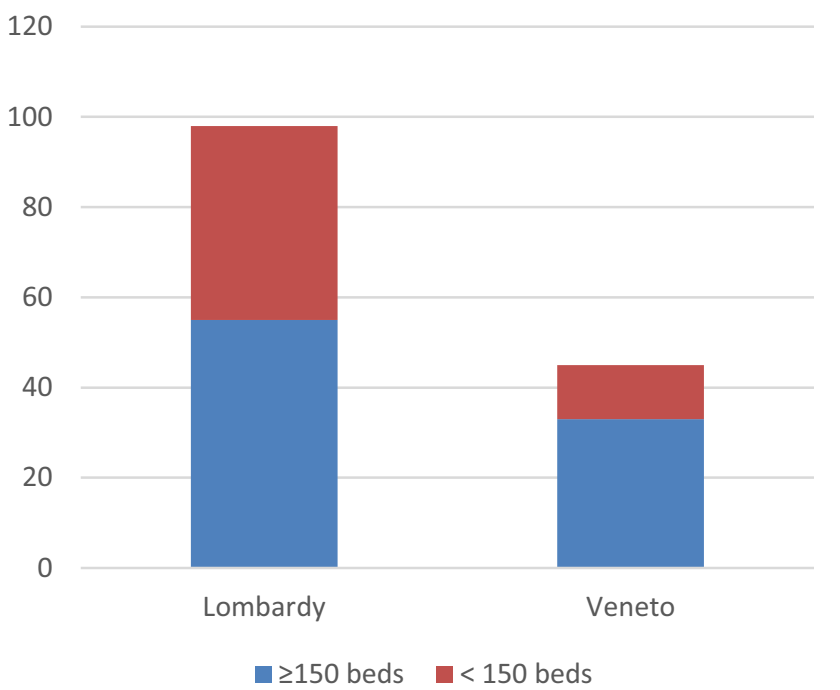

Fig. 2 Number of acute hospitals in Lombardy and Veneto regions by size (beds). The number of hospitals (43) in the figure does not coincide with that quoted in the text (36) for the Veneto region since two hospital trusts and five spokes have two sites each one (Sources: Lombardy: http://www.dati.salute.gov.it; Veneto: Allegato DGRV n. 22/CR del 13.03.2019)

reliant on market forces generated by the purchaser-provider split in the last decades, whilst the Scottish NHS has laid more emphasis on collaboration within the healthcare system [10].

Once agreed that the public sector is potentially the best 'insurer' to grant universal coverage and thus fund a national
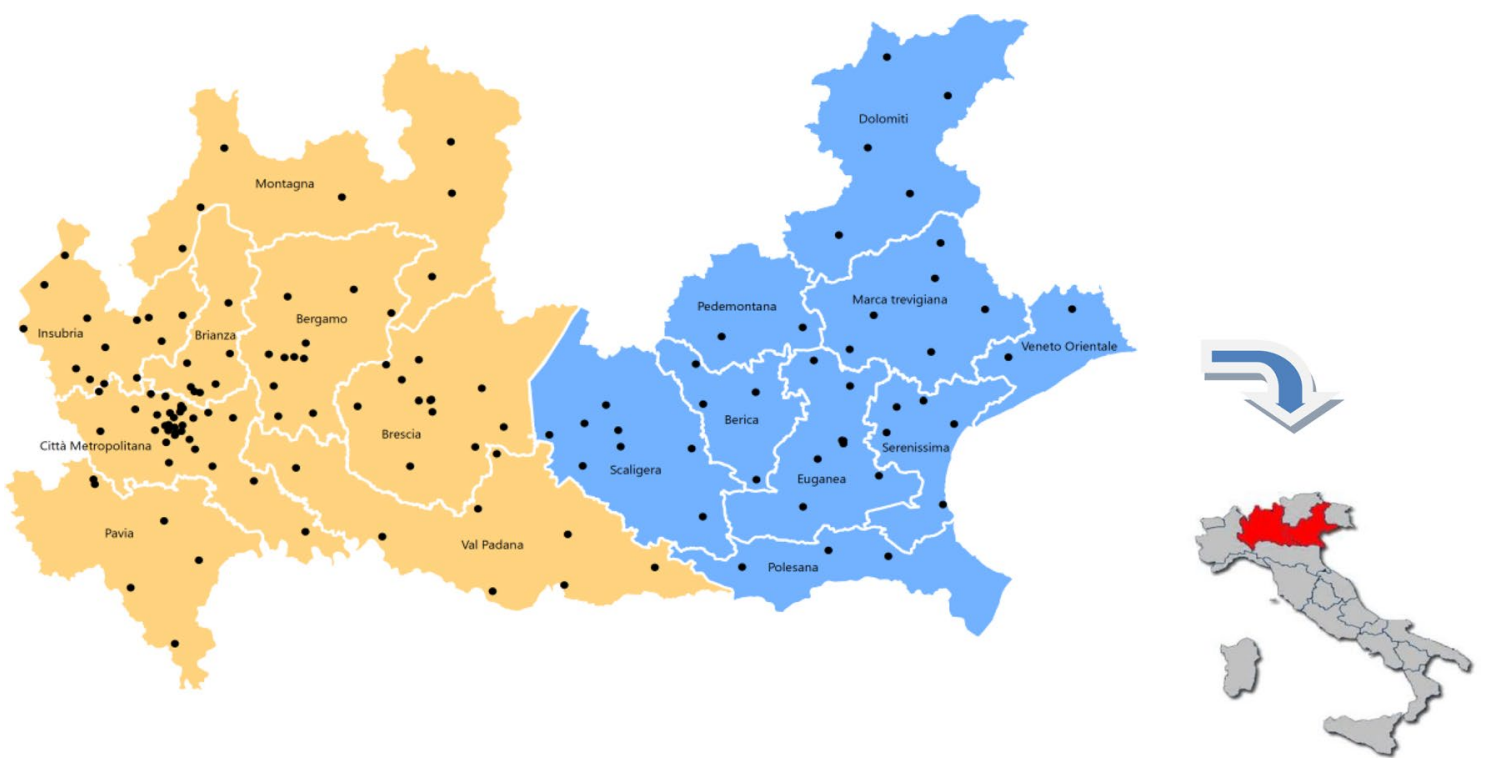

Fig. 1 Location of acute hospitals in Lombardy and Veneto regions. The number of hospitals (43) in the figure does not coincide with that quoted in the text (36) for the Veneto region since two hospital trusts and five spokes have two sites each one (Sources: Lombardy: http://www.dati.salute.gov.it; Veneto: Allegato DGRV n. 22/CR del 13.03.2019) 
health system, the choices to provide healthcare services are less obvious [11]. However, in a typical 'market failure' context such as health market, competition among providers is not justified by economic theory and required strong ideological support from the first British attempt in 1990. Free prices cannot be competitive, by definition, and setting them through regulation (e.g., tariffs for hospital services) is necessarily an arbitrary exercise, eventually distorting allocation of financial resources. Moreover, activity-based funding is likely to reward over-treatments and undermine coordination among health providers, eventually missing opportunities to improve quality and constrain costs.

On the other hand, it is fair to recognize that traditional public sector bureaucracy and political influence at all the NHSs tiers have fueled the myth of market competition as an alternative strategy. For instance, most efforts to plan rational public hospital networks by closing small acute hospitals in Italy - a historically rooted weakness throughout the country [2] — have failed mainly because of trade unions and political resistance, eventually leading to arguable reorganizations. Trades and shops around little hospitals have likely been the 'best allies' against their closure, in a country where around $90 \%$ of 7903 municipalities have less than 15,000 inhabitants. Last but not least, the appointments of general managers often based on political affiliations rather than professional skills have contributed to achieve these disappointing results.

Nevertheless, once ruled out competing and pricing for managing public healthcare services, planning and budgeting are the only solution, possibly in a climate of collaboration and integration among health professionals. Ideally, there is no doubt that an organizational culture rooted in collaborative teamwork fits healthcare services much better than a competitive one, eventually deterring modern 'side effects' like defensive medicine [12]. In practice, the big challenge of the future is to develop the best incentives for limiting political influence and administrative bureaucracy, the real 'devils in disguise' of the public sector, in order to efficiently manage the supply of healthcare services in Beveridge-type NHSs [11].

\section{Future prospects}

Accordingly, we conclude putting forward three proposals in this perspective, hopefully useful also for other European NHSs.

First, political governments should not be allowed to easily modify the baseline institutional framework of the NHS, neither for funding nor for provision of public healthcare services. The only welcome innovations in health should be scientific and technological, whereas economic innovations should be always considered very cautiously, open as they are to political influence. Notably, there should be 'safeguard clauses' for a few basic 'rules of the game', which should at least require very strong political support to be changed at the central level (e.g., two-third majority in the Italian Parliament). For funding, all citizens have to contribute to the costs of the NHS for social solidarity, no matter whether they use it or not. For provision, public and private healthcare services can co-exist, but separately, being the former the irreplaceable pillar of the NHS and the latter (better if non-profit ones) its supplement at most [11].

Second, it is quite evident that a re-balancing of services between primary care in community and secondary care in hospitals is needed in any healthcare system for the future [13]. Accordingly, the Italian NHS funding criteria should be targeted to constrain the latter and enhance the former, which are inevitably penalized by their lower costs under budget constraints and more in general by their low impact on local economies, especially in this period of unending financial crisis. At the same time, all general practitioners should become employees of the NHS, as their colleagues in hospitals, and should be located in centers of community care open all day long [14]. These sites should bring together all the health, social and administrative professionals working in primary care, and strive for better exploiting modern information technology tools like telemedicine.

Third, specific post-graduate education on healthcare should be mandatory for top managers appointed in the NHS, in order to limit political influence in selecting them and enhance specific management skills in the healthcare field. In Italy there have never been neither a national school of health nor teaching programs run in other bodies officially recognized and funded for educating the NHS managers. This specific education should make potential managers of healthcare services fully aware that patients are to be the primary interest of health professionals, as often recalled in the clinical literature [11]. So, financial incentives in health care should be considered arguable means to make the latter work harder for the former.

In conclusion, we firmly contend that the framework of a NHS has to remain public, by definition, and future analysis should focus only on how to improve and standardize the quality of community and hospital health services delivered in a modern perspective of integrated care.

Acknowledgements LG welcomes his new-born grand-child Michelotto into this world.

Funding No sources of funding were used to conduct this study or prepare this manuscript. 


\section{Declarations}

Conflict of interest Livio Garattini, Marco Badinella Martini and Michele Zanetti have no conflict of interest directly relevant to this article.

\section{References}

1. Garattini, L., Zanetti, M., Freemantle, N.: The Italian NHS: what lessons to draw from COVID-19? Appl. Health Econ. Health Policy 18(4), 463-466 (2020)

2. Ferre, F., de Belvis, A.G., Valerio, L., Longhi, S., Lazzari, A., Fattore, G., Ricciardi, W., Maresso, A.: Italy: health system review. Health Syst. Transit. 16(4), 1-168 (2014)

3. Garattini, L., Padula, A.: Clinical governance in Italy: 'Made in England' for import? Appl. Health Econ. Health Policy 15(5), 541-544 (2017)

4. Lal, A., Erondu, N.A., Heymann, D.L., Gitahi, G., Yates, R.: Fragmented health systems in COVID-19: rectifying the misalignment between global health security and universal health coverage. Lancet 397(10268), 61-67 (2021)

5. Pisano GP, Sadun R, Zanini M. Lessons from Italy's response to coronavirus. https://hbr.org/2020/03/lessons-from-italys-respo nse-to-coronavirus. Accessed 27 Mar 2020

6. Ghiotto, M.C., Rizzolo, Y., Gandolfo, E., Zuliani, E., Mantoan, D.: Strengthening primary care: the Veneto Region's model of the Integrated Medical Group. Health Policy 122(11), 1149-1154 (2018)

7. Rechel, B., Džakula, A., Duran, A., Fattore, G., Edwards, N., Grignon, M., Haas, M., Habicht, T., Marchildon, G.P., Moreno, A., Ricciardi, W., Vaughan, L., Smith, T.A.: Hospitals in rural or remote areas: an exploratory review of policies in 8 high-income countries. Health Policy 120(7), 758-769 (2016)

8. Toniolo, F., Mantoan, D., Maresso, A.: Veneto Region, Italy. Health system review. Health Syst. Transit. 14(1), 1-138 (2012)

9. AGENAS. http://www.quotidianosanita.it/allegati/allegato15 25662.pdf (2020). Accessed 10 Feb 2021

10. Hawkes, N.: How different are NHS systems across the UK since devolution? BMJ 346, f3066 (2013)

11. Garattini, L., Padula, A.: Competition in health markets: is something rotten? J. R. Soc. Med. 112(1), 6-10 (2019)

12. Garattini, L., Padula, A.: Defensive medicine in Europe: a 'full circle'? Eur. J. Health Econ. 21(2), 165-170 (2020)

13. Jones, R., Newbold, M., Reilly, J., Drinkwater, R., Stoate, H.: The future of primary and secondary care. Br. J. Gen. Pract. 63(612), 379-382 (2013)

14. Garattini, L., Badinella Martini, M., Zanetti, M.: More room for telemedicine after COVID-19: lessons for primary care? Eur. J. Health Econ. 22(2), 183-186 (2021)

Publisher's Note Springer Nature remains neutral with regard to jurisdictional claims in published maps and institutional affiliations. 